\title{
Never the right time: maternity planning alongside a science career in academia
}

\author{
Ebru Eren \\ School of Education, Trinity College Dublin, Dublin, Ireland
}

\begin{abstract}
Pregnancy and maternity planning pose a challenge and stress in the academic career of a researcher, especially at the $\mathrm{PhD}$ and postdoctoral level, where the conditions of employment and role status are not clear. This paper discusses how women evaluate maternity-related issues and balance their scientific career in the field of physics and the physical sciences from undergraduate to postdoctoral level. The paper tries to assess how this affects their progress in academic science. The data were generated through indepth individual interviews with 15 women from four universities in Dublin. The participants of this study were not necessarily mothers or mother-to-be. The findings indicate that compared to their male counterparts, the need to continually publish, the absence of paid parental leave, short-time positions, lack of clear institutional policies on maternity, lack of pregnancy-maternity friendly work plans and the non-extension of contracts, puts many female early-career scientists at an academic disadvantage, resulting in a leaky pipeline. This paper will offer a wider understanding of how instability intersecting with maternity, gender and gendered family responsibilities cause young women from undergraduate to postdoctoral level in science to reevaluate their academic career progression.
\end{abstract}

\section{Introduction}

In physics and the physical sciences where the gender gap is still significant in academia, particularly at the senior level, women may face challenges in progressing when they take maternity leave (Kuehn, 2018; Williams \& Ceci, 2012; Ysseldyk et al., 2019) and deal with maternity-related issues. Many of them even consider leaving academic science for more stable jobs.

Based on interviews with women, and my own experience as a pregnant PhD student, I realized how precarious the situation can be for women with temporary contract-based arrangements or with grants that do not make provision for paid parental time off from study/research or contract extension. Recently family-friendly policies and paid-paternity leave before and after pregnancy, and/or adoption, have been implemented in funding applications, but they remain thin on the ground. There is still a lack of continuity in the parental leave policies of universities and funding agencies in Ireland for postdoctoral researchers and graduate students, leading to a high level of insecurity and consequent strain, especially for women.

There are also questions of whether such women are supported by their supervisors/principal investigators, if they are hired after parental leave and; if they are financially assisted during the period of absence. The chances of being hired may be affected if the number of publications achieved has decreased due to pregnancy, maternity or care responsibilities. It is more complicated 
at $\mathrm{PhD}$ level since the researcher spends much of their time studying (at least three years) and has little or no advantages in terms of maternity or parental leave. The lack of proper pregnancy, maternity, and paternity leave schemes/policies, often dependent on sources of funding, contributes to early-career researcher uncertainty and dissatisfaction.

In this study, I focused on the lived experiences and perspectives of women in higher education (either as students or academics) in the field of physics and the physical sciences at Dublin universities. They were interviewed on the subjects of maternity, gendered parental responsibilities, pregnancy and parental leave. Particular attention was given to (1) work-life-family balance; (2) employment and working conditions and their influence on future progression in academia and (3) evaluation of parenthood, maternity, gender, and doing science in academia. The disciplines of physics and the physical sciences have been determined according to the HEA (Higher Education Authority in Ireland) 2017/2018 statistics of the new entrance, enrolments, and graduates by level, the field of study, and gender. The statistics of the HEA suggest that in physics and the physical sciences fields the gender gap is the highest of all scientific disciplines in Ireland. There are many different reasons for women's underrepresentation in these fields. By the time a woman reaches a senior-level position in academia, she faces, and has faced, many challenges. Maternity and childcare responsibilities are among these.

In this study, I used a critical feminist theoretical framework that addresses the interrelationships of gender, pregnancy, motherhood, parenthood, academic culture and policy in the quest to enhance women's status in academia. In this study, critical feminist theory positions the concept of the social construction of gender at the heart of the research, and focuses on the perception and experiences of women, with a critical look at women's situation, as well as motherhood, in the academy. It is also oriented towards social and structural change in gender regimes in universities which 'remain structured largely on the male lifestyle' (Armenti, 2004, p. 78).

Although there is a significant amount of study done of academic mothers there is a lack of voice for women who do not have children. My work also aimed to fill this gap in the literature on mothering and academia. I felt it would be especially important within a feminist context to give voice to both groups of women (parentsornon-parents) from undergraduate to earlycareeryears in academia.

\section{Literature review}

\section{The politics of motherhood from a feminist perspective}

The link between feminism and motherhood has been a complicated one. There has been no coherent and unified approach to motherhood from feminism. While mothering is considered to beoppressiveand restrictive towomen by some feminists, for othersit is seen as a significant source of power (Lázaro, 1986).

According to Rich (1986) motherhood has two meanings: 'the potential relationship of any woman to her powers of reproduction; and the institution which aims to ensure that potential and allwoman shall remain under malecontrol' (p. 13). Rich drewattention to women's experiences as mothers and society's expectations of them. What mothering meant to women who identified themselves as feminists has also been explored. For example, Gordon (1990) argued that experiences of mothers are much more complex; 'on one level women experience pleasure in maternal love and they welcome the responsibilities, on another level, they are aware that they carry out their responsibilities in a social, material and cultural environment which does not privilege children and mothers' (p.106).

From the early years of the 21st century, dominant ideas about women and children have been criticized as derived from white middle-class perspectives and assumptions (Kinser, 2010). Black and postcolonial feminist researchers and activists argue that 'universal maternal subjectivity produces a limited and exclusionary view of maternal experience' (Mack, 2018, p. 11). Other recent aspects of 
popular debate highlights the multiple dimensions of mothering including experiences of non-binary and queer mothers. From a queer perspective, the deconstruction of 'mother' as an essential and biological category must be addressed.

Recent scholarship on mothering within feminist studies addresses agency, experience, identity, and policy (O'Reilly, 2019; Westervelt, 2018). Feminists are leaning towards the idea of developing an integrated policy approach that recognizes the complexity of the mother's experiences and needs (O'Reilly, 2019). They have come to recognize a range of diversities among women as well as their needs, career plans, and decisions. In O'Reilly 's word (2019) it is matricentric feminism that 'positions mothers needs and concerns as the starting point for feminist theory and politics' (p. 20), which 'understands mothering to be culturally determined and variable' (p.18) and engages with it in terms of intersectionality (p. 20). From this perspective motherhood and maternity can be understood as a subject position that intersects with other subject positions in women's life.

Another view, as argued by Westervelt (2018), is that ideas and expectations around mothering impact all women, whether they have children or not. This point is central to the motherhood and parenting discussion in this study. As shall be seen from the women's narratives here all women whether they are mothers or not, or whether they wish to be mothers or not, are affected by the social and cultural construction of motherhood. The most significant contribution of this study to further motherhood studies lies in its inclusion of the viewpoint of women on mothering and parenting, as non-mothers or as women with no plans to have children.

\section{Motherhood and academia}

There has been a growing interest in the topic of motherhood, maternity, and parental leave in academia (Armenti, 2004; Castaneda \& Isgro, 2013; CohenMiller, 2014; CohenMiller et al., 2019; Grenier et al. 2008; Lynch, 2008; Ward \& Wolf-Wendel, 2012). The vast majority of these studies have focused on the experiences of mothers in academia. They have particularly examined the varied lived experiences of being both mothers and academics as well as the struggles they have confronted. They tend to look at the experience of academics and graduate students through workfamily balance, slow advancement, income disparity, and the impact of motherhood and pregnancy on women's academic life.

In general, the literature suggests that the most common challenges faced by academic mothers are the demanding nature of academic work, the ambiguity, and inconsistency, of parental-leave policies, lack of funding for graduate students and tension between family and professional goals (Conley \& Carey, 2013; De Casanova \& Brown, 2013).

CohenMiller et al. (2019) described mothers in academia as 'motherscholars' who are in a complicated position, 'being neither fully at home nor fully at work' (p. 638). Sutherland (2008, 2010) spoke of the social construction of the good mother ideology and its impact on the lives of mothers. Sutherland $(2008,2010)$ also referred to the uneasy tension between being a mother and being a PhD student in terms of devoting time to care and to work at the same time and noted how 'the halls of academy reward those who work the longest and produce most, mama-guilt can go both ways' (2008, p. 215).

Similarly, findings from a study of early-career academic mothers (Ward \& Wolf-Wendel, 2012) demonstrated the guilt felt by women whoperceived themselves to be spending toolittle time with their children and too little time on their academic work. In Ward et al.'s study, institutional context was found to shape the daily experience of being an academic and a mother and women were found to shoulder the primary responsibility of taking care of the children.

This paper differs from the above studies in several ways: (1) the participants are in the academic disciplines of physics and the physical sciences where the gender gap is highest among all scientific disciplines in Ireland; (2) the paper highlights more of their thoughts, evaluations of motherhood, maternity, parenting, and related issues and its impact on their advancement in academic science; (3) 
the participants did not have to be mothers/parents to be included in the interviews; (4) it particularly addressed the vague policies around maternity in academia in Ireland at PhD and postdoctoral level.

\section{Materials/methods}

There is one central research question for this study:

Q: How do female researchers and students in the field of physics and the physical sciences in higher education evaluate maternity, parenting, and parental leave based on their scientific discipline and gender identity?

The data for this study is derived from the author's PhD project that used an embedded single-case approach with an in-depth interview method. The research question presented above, and the findings presented in the next section, were a part of a sub-unit of a case study that investigated women's science identity development in higher education. This article was influenced and written based on the findings of the sub-unit that addressed 'maternity and care' as a challenge to women on the way to becoming an academic scientist and as a factor in shaping 'science identity'.

The narratives presented here are based on intensive individual interviews with 15 women. Participants were female undergraduates, graduate students and early career researchers who were enrolled in physics and physical sciences departments at four Dublin universities. This study used both purposive and self-selection samples. It sought to include women from the scientific disciplines in which the gender imbalance is the highest in Ireland. The sample is selfselective because only women who fell into the category above, and who expressed an interest in participating, were invited to be interviewed. In order to recruit the participants, an email, with a detailed explanation of the research, was sent to the head of the schools in the physics and physical science departments at the four research universities in Dublin. They then circulated the email to their students and staff. The women who volunteered were invited to interview.

Out of the 15 participants, five were undergraduate (Bachelor of Science) students, five were PhD students and five were postdoctoral researchers. Their ages ranged from 18 to 40 . At the time of the interview, not all of them were parents or parent-to-be. Only two of them were mothers. One of them reported that she was a single mother. None of them reported pregnancy at the time of interview. None of them reported a low income or any financial problems.

To preserve the anonymity of the participants each of them was assigned a pseudonym. Before each interview session protection of confidentiality was assured and an introduction to the study was given. This study received ethical approval from the authors' academic institution. The interviews were conducted in the spring semester of 2019 from early March to June. Each interview was digitally recorded and transcribed by the author. This study used a narrative discursive analysis technique. The discursive narrative analysis relies on a detailed analytic procedure which includes looking for common elements that occur across different interviews, as well as at different points in the same interview.

Specifically, the process included: reading through the printed transcripts; finding the areas of the printed transcripts that addressed maternity, parenthood in academia and mothers' roles; circling and making notes of significant statements and comparing the statements of women both within the same interview and across the interviews. I particularly paid attention to words commonly used to describe maternity, parenthood responsibilities, gender, and balancing academia and parenting. Five themes were identified through comparing and contrasting the participants' statements: (1) unclear maternity leave policies; (2) balancing motherhood and academic science; (3) gendered parenthood; (4) instability; (5) Pandora's box: Mia's experience. 


\section{Results}

\section{Unclear maternity leave practices}

Dee (post-doc) said that maternity and childcare were fundamental issues which neither the funding agencies nor institutions dealt with properly. She stated that the issues were circumvented and that there was an absence of clear policies. She added:

\footnotetext{
For the last place I worked, I was on the gender committee. They were discussing what maternity leave was and they said it depends on what grants you are on. They probably give you the leave, but luckily it hadn't been an issue yet. They had no plan. If it did happen, you would just have to ask in advance like, Oh, thinking of getting pregnant, so, could you let me knowif I have maternityleave, which is just sodisastrous on like all grades and no one would ever do that.
}

Dee used the term 'disastrous' to describe the lack of clarity over maternity policy and added that 'whenyou don't have propermaternityleaveandgood childcare, itmakespeople dropout because they can just get an easier job which is not so demanding on all their time'. She emphasized that the solution should come from the government rather than individual universities. In the interview with Dee, the emphasis was on the instability and uncertainty around the postdoctoral position; she suggested that women were welcomed to attempt to progress in academic science, but that they were not supported once there. Additionally, she remarked that not all women have children, but that many people deal with children. Regarding maternity-related challenges, Carol (post-doc) commented:

\footnotetext{
Maternity leave depends on certainfellowships. There is some maternity leave but only for six months and that will go against your time for research because you are stopping six months and sometimes six months can be alot. Meaning that you can't publishsomething. Isee friendshaving kids during their postdocand they are really struggling with having the time to do the research and having the time to dedicate to the baby. I think you really have to make a decision there.
}

Aine (PhD candidate) shared a similar view in terms of ambiguous maternity leave policies of higher education institutions:

Because there is no rule around maternity leave, people can get taken advantage of ... or you know, your position might be gone or maybe you might have your position, but by the time you come back, science has moved on so much that it is hard to catch up and, I think that would be something genuinely thought I would think about going forward.

For Aine, the uncertainty around maternity-related issues at the postdoctoral level created a barrier for women's progression in academic science. She added:

It is after the Ph.D. level that the majority of women in science just drops off massively. I think that is because women are thinking, what if I want to have a family and if I have a postdoc position, am I going to get maternity leave or am I going to be able to take time off? Am I going to take a year off? That is reallyhard. That is something that I would consider going forward. I think it would be something that would influence my decision.

The narrative aboveillustrates that women are morelikely tostep out of the research pipelineonce children, or even plans for children, exist. The uncertainties, including ' will I be able to get maternity leave?' and 'will I lose my academic position?', may limit the control that women have over their lives (professional and personal). Such conflict is sometimes referred to as an identity conflict or identity interference (Settles, 2004) between the identities of 'woman' and 'scientist'.

\section{Balancing motherhood and academic science}

The inferred meaning of 'decision' used by both Carol and Aine in the previous narratives suggests that women have to choose between career and family. Based on her own experiences as a mother, Amada (post-doc) explained that shemade decisions based on the needs of her child. The following exchange between participant and interviewer further explores the issue of the tensions between the identities of mother and scientist: 
Amada If you take care of your family, if you have a child at home, the number of journals that you publish goes down. That is one main thing that I feel. You always have to make your decision based on your child.

Researcher Do you think you are working harder than your colleagues?

Amada Yeah, definitely. Ihave to do twice [the] work. I have to gohome, teach my son, cook, and do all the household chores and come back here early in the morning. If I was single with no child, it would be much easier.

Neha (PhD candidate) was encountered in the middle of the interview process. She appeared to want to progress in academia but was uncertain about this due to the pressures of research, including the associated 'mental stress'. During our talk, she often used the word 'pressure' which she connected to motherhood. For her, maternity leave was a significant gap in the research process that interrupted women's publication record and ultimately destroyed their academic career. The following exchange encapsulates her position:

Neha: Iamnot sure, because of all thestress of the work, I am reallyconfused if I go for a postdoc, or maybe I just start in a company or management. The next step is not very clear to me in that situation.

Researcher: Would the idea of maternity affect that decision?

Neha: Yes, of course, it affects me. I think it will be hard because I do research in a lab and six months of maternity leave is a huge gap. For a postdoc, there is pressure to publish . . . and everything is pressure. I don't think you can enjoy motherhood like that.

Ale (PhD candidate) stated that maternity leave and related issues 'scared' her, but that it would not prevent her from pursuing her scientific career. Her construction of science identity collided with her gender identity as was the case for most of the participants. The responsibility for parental leave and childcare still fall overwhelmingly on women's shoulder creating tension between the gender and science identities of women. Ale's comments on this went as follows:

I know a lot of people who have said to our faces that [they] I would never hire awoman in science because what if you get pregnant and really stupid conversations. We were talking about getting maternity leave and stuff like that. It does kind of scare me a little bit. I know it is possible, but it is going to be hard.

Diane (BSC student) stressed age, parenthood responsibilities and gender as factors in careers in science. She said that 'the majority of workload tends to fall on the women'. Diane's image of women with children inscientific work was influenced by female professors who had donewell in balancing work and family. This way, the tension between 'scientist' and 'woman' could beblended to foster positive science identity development. In Diane's words:

I have spoken to female professors about how they balance their work-life with their family life because the majority of the workload of having children or that responsibility to take time off work tends to fall on the woman. So that can affect your career progression. If you take time off work are people gonna be less likely to hire me if I am about 30, because I think I am going to have kids. That sort of thing is a factor to be considered. And particularly seeing women who have done well and had kids is nice.

\section{Gendered parenthood}

Mia (post-doc) who had just returned to work from maternity leave referred to the gender role beliefs associated with this experience. Iasked her if her husband was willing to take parental leave to take care of the baby:

Researcher: Can he have any paternity leave? 
Mia: Even if he could have, I don't think he would take it. He is so involved, I mean he won't be able to take extended periods away

Researcher: Do you think you sacrificed . . . your work . . .

Mia:Yeah, inaway, itisnatural.ImeanIdon'tthinkitwasasacrifice. Itisjustthewayitissupposedto be. I mean it is good if he could help, occasionally, but I wouldn't swap with him in the care of ...

Caring was regarded here as a mother's job. Biological and social perceptions of motherhood have been central to feminist movements. The relationship between motherhood and nature has been historically, politically, socially, and philosophically constructed (Okin, 2013). When motherhood is framed as nature, the care work done by mothers and the rearing of children appears to be the responsibility of women (Neyer \& Bernardi 2011). The construction of motherhood with Mia suggested that we both thought about motherhood from a female-specific perspective rather than an interdependency and collective perspective. While I linked it with sacrifice, Mia explained it in the context of nature. However, even if Mia depicted motherhood as a natural and essentialist normative role, she explained the stereotypical view of 'men are better at science' not from an essentialist perspective but a social perspective of motherhood and maternity:

Maybe I have also accepted some of those stereotypes that men are better at science. I really attribute it now from my perspective to great extents to maternity-related issues. But I accept that.

Annie (BSc student) was one of the youngest of the women interviewed. She also emphasized the gender-stereotyped expectations associated with parenthood:

If you are doing research especially many hours spent outside the home, having a child is like a limitation for women, whereas if it was a man, they just let their wife take the responsibility.

Her use of the word 'limitation' for women coincided with Carol's use 'dedicate' (above) in respect of the assignment of time to childcare. Both constructed motherhood in terms of commitment of mostly women's time to children which distracted them from their research and participants remarked that this this was not the case for men.

Roda (BSC student) pointed to the gendered roles of parenthood and its influence on women working in science. She explained that the social role of motherhood and scientist may overlap at some point and be a barrier to women. The balance between simultaneous management of motherhood and scientist roles is explained in the following interview excerpt by Roda:

I know a lot of my friends, who are girls constantly have conversations about Oh my God I am going to study really hard for 15 years, get a really good job, but then going to have kids, I am just not going to work because even if you have maternity leave you are still gonna have a one-year-old, a two-year-old. I never hear male friends talking about that ever. They never seem to ever think that that will have to be a barrier to them succeeding ... I probably will want to have kids at some stage in my life and probably will really struggle to balance being at home with them and wanting to be a really good scientist or something. I don't think it is something that men consider. It could be because women are more maternal. That could be a natural thing as opposed to nurture.

For Roda the requirements for becoming a 'good scientist' included a commitment to science just as Carol had also explained (above). The tension described between balancing being at home with children and wanting to be a good scientist shows the challenge that arises when women are faced with reconciling family and scientific work. Roda's concern here focused on the gender-based segregation of parenthood which shaped the plans of women who wanted to progress in their careers:

I think definitely like 20-year old lads are not thinking about 15years-time when they have kids. That is the last thing for them. But I think it just forceswomen to bea lot more realistic and not beable todream asmuch, which I don't think is a good thing.

Julianne (PhD candidate) also referred to the gendered view of parenting when she was asked what it was like to be a woman in a scientific environment: 
So far, it has been good. I think the future will be less good in terms of if I want children it is me who takes responsibility for it. So, I can't be in academia cause if I have like a three-year contract, I can't have children.

Julianne's statement suggests that women and mothers have more in common than women and scientists. Much of the conflict that Julianne described arises from women still being considered to be the primary care-givers in families. Julianne places the responsibility for deciding to have children on women and their need for stability when taking that decision. If academia does not provide this, then she 'can't be inacademia'.

\section{Instability}

There was a general awareness among the participants that parenthood and pregnancy are one of the most apparent gendered factors affecting women's full participation and advancement in their careers in academic science; itself already unstable for early-stage researchers. Carol, Dee, Lou (postdocs), and Jill (PhD candidate) commented on the challenging nature of having a child, the instability of early-career researchers, and the commitment of time to work:

I think a woman has to decide not to have a family. This is the first thing that pops up through your mind if you reallywant topursueaveryhighlevel of positionbecauseyouneed tohavededicated time. It isalwayseasier for men (Carol)

I am not too much in a hurry. I am postponing having kids because I am afraid that it would impact my career. I would rather wait to have a permanent position before having a kid. (Lou)

As you hit a certain age and you either make a decision like, Ican have children and different job and everything will be a lot easier because you have no certainty that you will have a permanent position, possibly at the time when you want to have children (Dee)

That is the thing that annoys me the most about academia because we are not stable in our lives yet. I mean if you have got a post-doc position, you will have to move somewhere else maybe. I am gonna finish my Ph.D. when I am 30. If I wait until I finish my Ph.D. and then the postdoc to start a family, I am going to be old for that. Probably not too old, but older than I would want to. (Jill)

Reese (BSc student) established a connection between physics, academia and motherhood in the context of stability. She said that neither physics nor academia are a stable path for women if they want children. Just like other participants above, Reese talked about a specific period of time in which women can start a family. Her emphasis on the lack of stability in academia and physics, and the need for stability when a woman becomes a mother, demonstrates how mothers who are academics in physics are positioned as separate from fathers who are academics in physics. Women were presented as needing stability, since she provides her 'body', while men were presented as enjoying flexibility as he provides 'the money' in 'whatever way':

Physics is not a very stable, or academia is not a very stable path. I think you get like five-year contracts with academiaforacademicresearch. Sometimes you have tomovearound for that and ifyouareawoman, you have a period with when you can have a family and have kids. So, while a man could either wait a bit longer, he can provide money in whatever way, but he doesn't need to provide his body to do that, then he has a little bit more flexibility in terms of moving around. If you are planning on having a child, you need a little bit more stability than that.

Cultural beliefs about gender appear to play a significant role for women in choosing an academic science career. Reese did not claim to have experienced this directly but to have heard it from 'Women in STEM' groups and from the physics environment around her.

The repeated use of the term 'stability' by the participants in relation to motherhood show it to be a defining factor in assumed identities in academia. Particular attention is drawn here to Cuca's (BSC student) use of the terms: instability and academic career:

I don't think there is a lot of sustainability in academic careers. I think there are lots of four-year contracts and then you are left looking for another job. I am not interested in that instability. I can see all the different disparities 
between men and women, but I don't want that to be a defining factor in my life. I know probably will be like if I decided to have kids that would probably affect my career. That really annoys me. I like to put that in a box.

It can be seen from the discussion above that Cuca is frustrated that having children will affect her career because as a woman she is expected to take on more of the responsibilities. She knows that there are different expectations of men and women and she finds this annoying; she prefers to ignore this and put it 'in $a$ box'.

\title{
Pandora's box: Mia's experience
}

Mia's (post-doc) experience, as expressed below, encapsulates what is in this 'box':

\begin{abstract}
Last year, my real kind of significant experience of trying to secure funding ... Actually, I felt that I was rejected based on, to a great extent, my CV. It appeared not as independent, but actually, it was worse than that, because one of the referees kind of explicitly mentioned that I have two maternity leaves, but that cannot account for the kind of metrics which don't match with my colleagues from the same generation. After many years of postdocs and $\mathrm{Ph}$.D., that is a bit extreme for me that he pointed out what maternity leaves can account for in terms of citation. He was saying, Oh, look at that guy, he has almost ten times the amount of your citations, you cannot explain this by maternity leave. I guess I do. You can't really give the same credit to men and women who have children. It is not the same thing.
\end{abstract}

Mia expressed her disappointment upon hearing one of her referees comparing her with a male academic from the same generation who was alleged to have had ten times more citations than she did. She described it as 'extreme' after many years of commitment to science as a researcher. She linked her rejection from the funding body with the number of citations and publications on her CV which, for her, may be explained by her maternity leave. She did not directlystate this connection, although she alluded to this through the number of citations and publications on her CV. She felt that male colleagues had a better chance of being hired/securing funding as they had not been equally affected by parental leave.

In line with earlier studies (Goulden, Mason, \& Frasch, 2011; Resmini, 2016) and as can be seen from Mia's narratives, maternity leave may lead a woman to have fewer publication than men. Because of career breaks taken by women and the family commitments they may have, or the perception of these by others, men have been found to be more likely to obtain a permanent academic position if a child arrives within five years of obtaining their doctoral degree (Mason et al., 2004).

\section{Discussion and conclusion}

There was a general agreement here about the significant impact of motherhood and parenting responsibilities on women's science careers in academia. During the interviews, maternity and parenthood related concerns were discussed by the participants regardless of their age, parenthood status, and level of study/academic career. It was notable that even the youngest participants expressed concerns regarding the possibility of combining children with optimal career progression.

The findings obtained from the interviews with undergraduate students revealed that instability and the prospect of parental responsibilities seemed to affect future career choice. Participants were often reluctant to pursue academic science careers due to the use of temporary contracts and the consequent instability. Comments from all participants also indicated that traditional gender role beliefs still existed and put particular stress on women.

When it came to employment and parental leave plans, being a post-doc and/or PhD candidate led to uncertainty. These participants particularly commented on the challenge of being a mother and a researcher in academia, the ambiguous parental leave policies and early career instability. During early career most participants reflected on the tension in balancing care/home duties with being a good scientist. In general, responses from the participants revealed that science requires 
particular dedication and that traditional gender responsibilities were not compatible with women's science identity or scientific career aspirations.

All participantsin thisstudy indicated thestruggle to progress in academia whenearlyemployment is based on short-term contracts which do not provide stability to early-career researchers. The narratives of the participants centred on the issues of pressure to publish, a scarcity of role models, lack of job stability/use of short-term contracts, vague policies around parental leave, work-life balance and disparities between the respective expectations of men and women in terms of child-care and parental responsibilities. Some of the participants also stated that taking some time off from scientific research can harm women's career progression in academia often due to there being no guarantee that a position would be found after maternity leave. This forces women to choose between a career in academia and parenthood. From the analysis of these narratives, I conclude that women remain uncertain about whether parental leave periods are managed professionally and appropriately (or at all).

Participants felt that gender affected their academic experience to a significant extent. From their perspectives, the identities of a scientist and a mother overlap and shape both their science identity and their career progression. The responsibilities for child-care are seen to fall disproportionately on women.

The participants compared men and women in terms of their responsibilities by giving examples from their own life, colleagues, lecturers and friends. From analysis of their narratives, and from the data more widely available, itseems that in physics and the physical science disciplines women are under-represented at all levels. Parenthood is another hurdle for women in particular if parents are not supported by their institution or if parenthood is strongly linked to traditional gender roles. Societal expectations and attitudes which assign distinctive gender roles and responsibilities still have disproportionately negative effects on women. Some participants referred to a 'maternal instinct' while others specifically indicated that gender role assumptions associated with women's maternity and caring are not inherent female traits, but culturally and socially constructed.

It was not the intention of this study to state that all women wish to become mothers, but that those that do meet unfair challenges when trying to combine (or planning to combine) science careers and motherhood. The societal norms and attitudes that assign distinctive gender expectations to individuals are still not sufficiently questioned and traditionally women have been expected tocommitmore timeto theirchildrenand the home. Thetransformation of theseviews is alongway from complete. The key to solving this is for academic institutions to establish policies for early- career researchers which encourage the best researchers to continue in academia rather than perpetuate gender-based sacrifices.

\section{Acknowledgments}

I am extremely grateful to the women who participated in my study and shared their opinions and lived experiences with me. I am positive that their voices will make a difference in the lives of academic women in science in terms of balancing academia and motherhood.

\section{Data availability statement}

The data for this article are confidential. The data generated during and/or analysed during the current study are available from the corresponding author on reasonable request.

\section{Disclosure statement}

No potential conflict of interest was reported by the author.

\section{Funding}

This article itself is not supported by any funding agency. 


\section{Notes on contributor}

Ebru Eren has a Ph.D. from the School of Education, Trinity College Dublin. She received her Bachelor's Degree from the Faculty of Education, Hacettepe University, Turkey in 2007 and her Master's Degree in Women's Studies from Istanbul University, Turkey in 2016. Before starting her Ph.D., she worked as a secondary school teacher for 10 years. She is particularly interested in postcolonial and feminist philosophy of science, identity development, higher education, Queer theory, and feminism.

\section{ORCID}

Ebru Eren http://orcid.org/0000-0001-6098-0379

\section{References}

Armenti, C. (2004). Women faculty seeking tenure and parenthood: Lessons from previous generations. Cambridge Journal of Education, 34(1), 65-83.

Castaneda, M., \& Isgro, K. (Eds.). (2013). Mothers in academia. New York, USA: Columbia University Press.

CohenMiller, A., Demers, D., Gorvine, M. M. , Zaller, N. D., Hudson, H. K. , Kennedy, L. A., ... Sanders, S. (2019). Conflicting roles of mother and academic? Exploring the use of arts-based self-care activities to encourage wellbeing. art/ research international. A Transdisciplinary Journal, 4(2).611-645.

CohenMiller, A. S. (2014). The phenomenon of doctoral student motherhood/mothering in academia: Cultural construction, presentation of self, and situated learning (Doctoral dissertation). The University of Texas, Texas, United States.

Conley, C. S., \& Carey, D. C. (2013). Academic mothers on leave, on the line: Toward improving parental-leave policies and practices. In Castaneda, M. \& Isgro, K. (Eds.), Mothers in academia (pp. 200-212). New York, USA. Colombia University Press E-book.

De Casanova, E., \& Brown, T. M. (2013). Making it work: Success strategies for graduate student mothers. In Castaneda, M. \& Isgro, K. (Eds.), Mothers in academia. New York, USA: Colombia University Press E-book.

Gordon, T. (1990). Pleasures and gains: Contradictions and difficulties. In Feminist mothers. Women in Society. London: Palgrave. doi:10.1007/978-1-349-20292-8_8

Goulden, M. , Mason, M. A. , \& Frasch, K. (2011). Keeping women in the science pipeline. The Annals of the American Academy of Political and Social Science, 638(1), 141-162.

Grenier, R. S., \& Burke, M. C. (2008). No margin for error: A study of two women balancing motherhood and Ph. D. studies. The Qualitative Report, 13(4), 581-604.

Higher Education Authority. (2017/2018). HEA statistics archive. (2017/18). Retrieved from http://hea.ie/statistics-archive /2017-18-graduates/

Kinser, A. E. (2010). Motherhood and feminism. Berkeley: Seal Press.

Kuehn, B. M. (2018). Scientist and Parent: Looking for the best of both worlds. Elife, 7, e36366.

Lázaro, R. (1986). Feminism and motherhood: O’Brien vs beauvoir. Hypatia, 1(2), 87-102. Retrieved from http: //www. jstor.org/stable/3809898

Lynch, K. D. (2008). Gender roles and the American academe: A case study of graduate student mothers. Gender and Education, 20(6), 585-605.

Mack, A. N. (2018). Critical approaches to motherhood. In D. Cloud (Ed.), The oxford encyclopedia of communication and critical cultural studies. Oxford University Press. Retrieved from https://www.oxfordreference.com/view/10.1093/ acref/9780190459611.001.0001/acref-9780190459611

Mason, M. A. , \& Goulden, M. (2004). Marriage and baby blues: Redefining gender equity in the academy. Annalsof the American Academy of Political and Social Science., 596(1), 86-103.

Neyer, G. \& \&ernardi, L. (2011). Feministperspectiveson motherhoodand reproduction. Historical Social Research, 36(2), 162-176.

O'Reilly, A. (2019). Matricentric feminism: A feminism for mothers. Journal of the Motherhood Initiative for Research and Community Involvement, 10(1/2), 13-26.

Okin, S. M. (2013). Women in western political thought. New Jersey, USA: Princeton University Press.

Resmini, M. (2016). The 'Leaky Pipeline'. Chemistry A European Journal, 22(11), 3533-3534. https://doi-org.elib.tcd.ie/10. 1002/chem. 201600292

Rich, A. (1986). Of woman born: Motherhood as experience and institution. New York, NY: WW Norton and Company.

Settles, I. H. (2004). When multiple identities interfere: The role of identity centrality. Personality \& Social Psychology Bulletin, 30(4), 487-500.

Sutherland, J. A. (2008). Ideal mama, ideal worker: Negotiating guilt and shame in academe. In E. Evans \& C. Grant (Eds.), Mama, PhD: Women write about motherhood and academic life (pp. 213-221). New Brunswick: Rutgers University Press. 
Sutherland, J. A. (2010). Mothering, guilt and shame. Sociology Compass, 4(5), 310-321.

Taylor, S., \& Littleton, K. (2006). Biographies in talk: A narrative-discursive research approach. Qualitative Sociology Review, 2(1), 22-38.

Ward, K., \& Wolf-Wendel, L. (2012). Academic motherhood: How faculty manage work and family. New Brunswick, NJ: Rutgers University Press.

Westervelt, A. (2018, May 26). Is motherhood the unfinished work of feminism? The Guardian. Retrieved from https: / / www.theguardian.com/commentisfree/2018/may/26/is-motherhood-the-unfinished-work-offeminism

Williams, W. M. \& \& Ceci, S. J. (2012). When scientists choose motherhood: Asingle factor goes a long way in explaining the dearth of women in math-intensive fields. How can we address it? American Scientist, 100(2), 138.

Ysseldyk, R., Greenaway, K. H., Hassinger, E., Zutrauen, S., Lintz, J., Bhatia, M. , ... Tai, V. (2019). A leak in the academic pipeline: Identity and health among postdoctoral women. Frontiers in Psychology, 10, 1297. 